\title{
DESENCONTROS ENTRE IDENTIDADE, FORMAÇÃO E PRÁTICA: A PSICOLOGIA NA ASSISTÊNCIA SOCIAL DE NOVA FRIBURGO'
}

\author{
DESAJUSTES ENTRE IDENTIDAD, FORMACIÓN Y PRÁCTICA: LA PSICOLOGÍA EN \\ LA ASISTENCIA SOCIAL DE NOVA FRIBURGO
}

MISMATCHES BETWEEN IDENTITY, TRAINING AND PRACTICE: PSYCHOLOGY IN THE SOCIAL ASSISTANCE OF NOVA FRIBURGO

DOI: $10.22481 /$ rbba.v1i02.7798

Rafael Reis da Luz

Universidade Federal do Rio de Janeiro - Brasil ORCID: https://orcid.org/0000-0003-2330-7761

Lattes: http://lattes.cnpq.br/4223641834759794 Endereço eletrônico: rafaelreisdaluz@gmail.com

Ana Carolina Pereira Marchesini Universidade Estácio de Sá - Brasil ORCID: https://orcid.org/0000-0003-4479-5602

Lattes: http://lattes.cnpq.br/0830465638617021 Endereço eletrônico: anamarchesini1087@gmail.com

Matheus Breder Coutinho Hille Universidade Estácio de Sá - Brasil ORCID: https://orcid.org/0000-0002-3406-418X Endereço eletrônico: matheus.hille@gmail.com

\begin{abstract}
RESUMO
O presente estudo é um recorte exploratório de pesquisa que buscou sistematizar saberes e práticas de Psicologia Comunitária nos serviços do município de Nova Friburgo, Rio de Janeiro, Brasil. No presente texto, o objetivo é analisar as entrevistas de oito profissionais de Psicologia inseridas nos equipamentos da
\end{abstract}


assistência social, aprofundando a discussão no que tange à formação, prática e identidade profissional, destacando limites e possibilidades da práxis psicológica na assistência social. As entrevistas foram transcritas e submetidas à análise de conteúdo. Apontamos que os embates nas representações da identidade profissional são em parte reflexo de um tensionamento entre a formação em Psicologia e o que é esperado em uma política de assistência social. Dentre as considerações finais, indicamos que o trabalho da Psicologia na assistência social de Nova Friburgo se encontra em delicada construção, permanecendo a necessidade de crítica, revisão e superação de apropriações teórico-metodológicas presentes nas ciências psicológicas que fundamentam práticas descontextualizadas e psicologizantes.

Palavras-chave: Políticas Públicas; Assistência Social; Psicologia.

\title{
RESUMEN
}

El presente estudio es una parte exploratoria de la investigación que buscó sistematizar conocimientos y prácticas de Psicología Comunitaria en los servicios del municipio de Nova Friburgo, Río de Janeiro, Brasil. En el presente texto, el objetivo es analizar las entrevistas de ocho profesionales de la Psicología insertos en el equipamiento asistencial social, profundizando la discusión sobre la formación, práctica e identidad profesional, destacando los límites y posibilidades de la praxis psicológica en la asistencia social. Las entrevistas fueron transcritas y sometidas a análisis de contenido. Señalamos que los enfrentamientos en las representaciones de la identidad profesional son en parte reflejo de una tensión entre la formación en Psicología y lo que se espera en una política asistencial. Entre las consideraciones finales, señalamos que el trabajo de Psicología en asistencia social en Nova Friburgo se encuentra en construcción delicada, con la necesidad de crítica, revisión y superación de las apropiaciones teórico-metodológicas presentes en las ciencias psicológicas que subyacen a las prácticas descontextualizadas y psicologizantes.

Palabras clave: Políticas Públicas; Assistencia Social; Psicología.

\begin{abstract}
The present study is an exploratory part of research that sought to systematize knowledge and practices of Community Psychology in the services in Nova Friburgo, Rio de Janeiro, Brazil. In this present text, the objective is to analyze the interviews of eight Psychology professionals inserted in the social assistance equipment, deepening the discussion regarding training, practice and professional identity, highlighting the limits and possibilities of psychological praxis in social assistance. The interviews were transcribed and submitted to content analysis. We point out that the clashes in the representations of professional identity are partly a reflection of
\end{abstract}


a tension between the formation in Psychology and what is expected in a social assistance policy. Among the final considerations, we indicate that the work of Psychology in Social Assistance in Nova Friburgo is in delicate construction, with the need for criticism, review and overcoming of theoretical and methodological appropriations present in the psychological sciences that support decontextualized and psychologizing practices.

Key words: Public Policy; Social Assistance; Psychology.

\section{INTRODUÇÃO}

Este estudo é um recorte exploratório da pesquisa "Saberes e Práticas em Psicologia Social Comunitária em Nova Friburgo, RJ”, vinculada ao Programa de Pesquisa Produtividade da Universidade Estácio de Sá (UNESA) e realizada ao longo de 2018 e 2019. A pesquisa teve como objetivo principal sistematizar saberes e práticas de Psicologia Comunitária nas políticas, serviços, instituições e iniciativas públicas, privadas e filantrópicas no município de Nova Friburgo, na região serrana do Estado do Rio de Janeiro. O projeto foi aprovado pelo Comitê de Ética em Pesquisa da UNESA e contou com a participação de dez discentes voluntários do curso de graduação em Psicologia, campus Nova Friburgo.

A fase inicial da pesquisa consistiu em um levantamento e análise sistemáticos de artigos científicos na base SciELO (Scientific Electronic Library), dos últimos cinco anos. Tal empreendimento teve o intuito de delinear uma construção teórica do campo, identificar aspectos diferentes e não antevistos na questão e objetivos da pesquisa e auxiliar na elaboração do roteiro de entrevista. Na segunda fase, realizamos 60 entrevistas com 58 psicólogas (duas possuíam vínculo em duas instituições), desigualmente distribuídas em 27 iniciativas, serviços, equipamentos e instituições públicas, privadas e filantrópicas. O material foi transcrito e submetido à análise de conteúdo, na perspectiva de Bardin (2016). Dentre as conclusões, apontamos o desafio no cumprimento de metas quanto à plenitude da formação e preparação das profissionais, visando maior compromisso social da Psicologia com os grupos e comunidades que têm sido alvo de seus trabalhos. Tal desafio se destacou no campo das políticas públicas, onde os discursos indicavam que limitações tanto institucionais quanto da formação impunham significativas restrições a um trabalho psicológico voltado para a perspectiva social comunitária. 
NA ASSISTÊNCIA SOCIAL DE NOVA FRIBURGO

No presente texto, nosso empreendimento é outro: retornamos ao material da pesquisa de campo e destacamos a análise de oito entrevistas, aquelas realizadas com as profissionais inseridas, na época, nas políticas socioassistenciais do município. A partir desse destaque e de bibliografia específica, propomos uma discussão sobre o histórico e as problemáticas que envolvem a inserção e atuação da profissional ${ }^{\mathrm{ii}}$ de Psicologia no Sistema Único da Assistência Social (SUAS). Dentre as categorias elencadas no processo de análise de conteúdo, selecionamos para o presente recorte a categoria identidade profissional, assim como suas subcategorias formação e prática profissionais. A categoria identidade profissional, desenvolvida na pesquisa, delineia o perfil das profissionais entrevistadas, perfil que é ativamente construído por elas, enquanto as subcategorias formação e prática remetem a diferentes aspectos que integram e fundamentam essa identidade. Como veremos, essas categorias formam uma práxis da Psicologia no contexto da assistência social, expressando tensionamentos que muito falam dos desencontros de certa Psicologia, leia-se hegemônica, nas políticas públicas de assistência social, sendo este um campo de atuação voltado para intervenções não psicologizantes, não individualistas e não tecnicistas.

Este recorte exploratório surgiu da necessidade de maior reflexão sobre a participação da profissional de Psicologia nas referidas políticas, tendo em vista que os desafios das práticas psicológicas, na pesquisa, apresentaram-se com maior ênfase nesse contexto. Ao discutir as problemáticas que permeiam esta participação, a presente proposta visa fomentar o desenvolvimento de práticas coadunadas com as premissas das políticas sociais, além de mais comprometidas com a mudança social. Para tanto, realizamos uma breve apresentação histórica das políticas sociais no Brasil, destacando a contribuição da Psicologia. Posteriormente, apresentamos e discutimos as entrevistas a partir das referidas categorias de análise.

\section{Políticas sociais e Psicologia: breve histórico}

Ao examinar o contexto do desenvolvimento das políticas sociais no Brasil e a trajetória da Psicologia neste campo, nota-se que esta se insere de forma mais ordenada no campo do bem-estar social público em meados da década de 1980, período de transição democrática, onde eram predominantes práticas elitistas, individualizantes e populistas nas políticas sociais (CAMARGO; MENZ, 2020; ROMAGNOLI, 2006; SCOTT et al., 2019; YAMAMOTO; OLIVEIRA, 2010). 

NA ASSISTÊNCIA SOCIAL DE NOVA FRIBURGO

No tocante à assistência social, Yamamoto e Oliveira (2010) apontam que ela estava associada, inicialmente, a uma prática de caridade, pautada numa lógica da tutela, do favor e do clientelismo. Nesse sentido, a assistência social remetia à ideia de ajuda e bondade ao invés de ser compreendida como um direito de cada indivíduo enquanto cidadão. Com a Constituição de 1988, ocorreram avanços significativos no Sistema de Proteção Social Brasileiro, efeito do reconhecimento do direito social como um dos principais focos da Seguridade Social. Tal reconhecimento partiu de esforços no tocante à superação do caráter assistencialista e clientelista que se fazia presente na proteção social. Logo, ainda que as políticas sociais tenham continuado relativamente fragmentadas, compensatórias, setorizadas e seletivas, o Brasil delineava um Sistema de Proteção Social que se aproximava do modelo do Estado de bem-estar social.

Com a Constituição 1988, é instituído o sistema da Seguridade Social, incluindo a assistência social, saúde e previdência social, tendo como princípios básicos a universalidade e a equidade, e passando a ser caracterizada como um direito de todo cidadão. No entanto, a assistência social somente foi validada enquanto política pública integrante da Seguridade Social em 1993, com a regulamentação da Lei $n^{\circ}$ 8.742, de 7 de dezembro de 1993, que inaugurou a Lei Orgânica de Assistência Social (LOAS) e instituiu o Conselho Nacional de Assistência Social (CNAS), seguida da criação da Política Nacional de Assistência Social (PNAS) e a Norma Operacional Básica (NOB-SUAS/2005) (BRASIL, 2004, 2005).

O Sistema Único de Assistência Social (SUAS) é destinado a garantir a proteção social, cujas ações são organizadas por nível de complexidade na Proteção Social Básica (PSB) e Proteção Social Especial (PSE). A PSB tem como porta de entrada os Centros de Referência de Assistência Social (CRAS) e é direcionada à população em situação de vulnerabilidade social, tendo suas ações destinadas à prevenção dos riscos sociais através do fortalecimento de vínculos e promoção da autonomia. A PSE é dividida em proteção social especializada de média complexidade e de alta complexidade. A primeira é integrada pelos Centros de Referência Especializados da Assistência Social (CREAS), que oferecem serviços e programas direcionados à população cujos direitos foram violados e que estão em situação de risco pessoal e social, oferecendo acompanhamento técnico especializado. A segunda é direcionada à população cujos vínculos familiares foram rompidos e é constituída por serviços e instituições de acolhimento provisório e de garantia da proteção integral (BRASIL, 2004, 2006, 2010). 
NA ASSISTÊNCIA SOCIAL DE NOVA FRIBURGO

Na década de 1990, como consequência da discussão e divulgação de trabalhos voltados para diferentes setores da população, estabeleceu-se a atuação de profissionais de Psicologia, e nesse momento, a Psicologia adentrou as políticas de bem-estar social, dentre outras (FREITAS, 2007). Não obstante, a inserção da Psicologia nas políticas públicas de assistência social se consolidou a partir de 2005 com a implementação da NOB-SUAS/2005 (BRASIL, 2005), fundamentada na PNAS, em 2004.

No entanto, como afirmam Yamamoto e Oliveira (2010, p. 19), a atuação psicológica na assistência social não possuía modelos norteadores, pois este setor, "diferentemente da saúde, avançou pouco na consolidação de condições de trabalho que favoreçam a manutenção de profissionais qualificados". Ademais, apesar do trabalho da psicóloga ter se inserido há algum tempo na proteção social, especialmente em políticas focalizadas, não houve uma sistematização na literatura acerca dessa inserção. Tal fato coaduna com o apontamento de Cordeiro (2018), que realizou uma revisão da bibliografia sobre a inserção da Psicologia no SUAS e encontrou considerável heterogeneidade de referenciais teórico-metodológicos que embasam as publicações analisadas - o que, até certo ponto, é característico do campo de conhecimento da Psicologia -, além de textos que não explicitam seus referenciais.

Diante dessa realidade, referências técnicas foram publicadas pelo CFP e pelo Centro de Referência Técnica em Psicologia e Políticas Públicas (CREPOP) para orientar as práticas no âmbito da assistência social. Tais publicações podem ser encontradas no site do CFP, que em 2016 publicou a "Nota técnica com parâmetros para atuação das (os) profissionais de psicologia no âmbito do Sistema Único de Assistência Social (SUAS)", com o objetivo de acrescentar referências técnicas sobre a atuação das profissionais de Psicologia no SUAS, publicadas pelo CREPOP. A referida nota foi resultante de uma investigação acerca da atuação da Psicologia no campo da assistência social durante os nove anos desde a publicação da primeira nota técnica, em 2007. O documento propõe a promoção de reflexões críticas no sentido de potencializar práticas comprometidas com o fortalecimento dos usuários, compreendidos como sujeitos de direitos, além da promoção de transformações concretas na vida destes sujeitos. Nesse sentido, cabe às psicólogas inseridas no campo das políticas de assistência social construir práticas que sejam contextualizadas com a realidade apresentada, práticas politizadas e embasadas em reflexões críticas, e que estejam constantemente problematizando seus efeitos. Nesse sentido, é papel da profissional de Psicologia inserida 


\section{NA ASSISTÊNCIA SOCIAL DE NOVA FRIBURGO}

nessas políticas a construção de intervenções psicossociais e não a aplicação da psicoterapia (CFP, 2016).

Contudo, conforme apontam Macêdo et al. (2015), este novo campo de atuação traz consigo problemas de ordem epistemológica, metodológica e prática, reflexo de uma formação em Psicologia escassa de referências teórico-metodológicas para uma prática comprometida com a transformação social. Nesse ínterim, a inclusão e o aumento das demandas no âmbito das políticas sociais têm levado à necessidade de reflexões que deem base às práticas psicológicas nas ações e serviços de assistência social. A partir deste cenário, o presente recorte de pesquisa surgiu da necessidade de refletir sobre a inserção e atuação da profissional de Psicologia no Sistema Único da Assistência Social (SUAS) a partir da experiência analisada em Nova Friburgo, em 2018. Esta reflexão é apresentada e discutida a seguir.

\section{Identidade, formação e prática: (des)encontros da Psicologia na assistência social}

A pesquisa realizada em 2018 teve como objetivo principal a sistematização de saberes e práticas do campo teórico-metodológico da Psicologia Comunitária nas políticas, serviços, instituições e iniciativas públicas e privadas no município. Muitas foram as categorias criadas a partir da análise de conteúdo, na pretensão de dar conta dos muitos e múltiplos tensionamentos que se apresentaram nos relatos dos 58 profissionais entrevistados. Nesse material, no entanto, chamaram atenção algumas problemáticas envolvendo práticas psicológicas nas políticas sociais, expressas principalmente nas categorias de análise identidade profissional e suas subcategorias formação e prática. O termo identidade se aproxima da noção de identidade social, que confere individualidade, auto referenciação e representatividade ao sujeito inserido em um meio que o influencia. Enquanto a categoria identidade professional delineia o perfil das profissionais entrevistadas, perfil que é ativamente construído por elas, as subcategorias formação e prática remetem a diferentes aspectos que integram e fundamentam essa identidade. Em conjunto, essas categorias de análise formam uma práxis da Psicologia no contexto da assistência social, refletindo-se em modos específicos de atuação, assim como construção de realidades e possibilidades específicas. Herança da tradição marxista, práxis é um conceito que remete à interseção entre teoria e prática, à síntese entre ser, pensar e estar no mundo (PEREIRA; ROCHA; CHAVES, 2016). Nesse sentido, práxis coloca teoria e prática num mesmo patamar, de modo a pensá-los em conjunto e não dissociados. $\mathrm{O}$ fazer, assim como o 
NA ASSISTÊNCIA SOCIAL DE NOVA FRIBURGO

pensar, é um ato reflexivo que constrói realidades objetivas e subjetivas, de modo que o sujeito não é dissociado da sua ação no mundo, de seu trabalho.

Neste tópico, detemo-nos na análise do recorte das entrevistas das oito profissionais atuantes na assistência social de Nova Friburgo, tendo como base metodológica a Análise de conteúdo, de Bardin (2016). Conforme estabelece esta autora, a análise categorial consiste na criação de categorias e subcategorias que têm como função reagrupar elementos de texto que apresentam proximidade temática. $\mathrm{O}$ processo de categorização ocorre por operações de desmembramento do texto em unidades que são reagrupadas por analogia ou similitude, além de outros critérios, previamente definidos. Atrelada à análise categorial, a análise temática consiste no critério semântico do processo de categorização, cujo intuito é descobrir núcleos de sentido que compõem a comunicação. Através dos temas, que podem ser frases ou palavras, a análise temática estabelece unidades de significação que se libertam do texto analisado segundo especificidades da teoria que guia a leitura.

O município de Nova Friburgo, onde foi realizada a pesquisa, compõe a região serrana do Rio de Janeiro, contando com aproximadamente 190 mil habitantes, segundo o Instituto

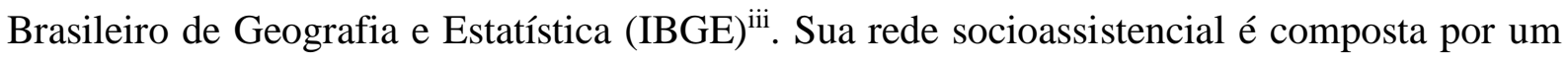
CRAS, um CREAS, um Centro de Cidadania LGBT, um Centro de Referência Especializado da Mulher (CREM), voltada para mulheres em situação de violência de gênero, e uma Casa de Acolhimento Institucional, voltada para crianças e adolescentes em risco psicossocial. As oito profissionais de Psicologia estavam distribuídas de forma homogênea nessa rede e apresentavam abordagens teóricas e especialidades variadas. Também foram identificadas consideráveis diferenças entre elas quanto ao tempo de formação e experiência, o que reforçou nossa escolha em desenvolver uma análise a respeito das categorias identidade, formação e prática, que parecem se imbricar e atravessar toda a trajetória da Psicologia no SUAS, como discutiremos a seguir.

De forma geral, como público alvo de seus equipamentos, as entrevistadas citaram pessoas e famílias que se encontram em situação de vulnerabilidade e risco, seja por perda ou fragilidade de vínculos, exclusão social por questões identitárias em termos étnico, cultural e sexual, falta de acesso aos serviços de saúde, baixa escolaridade, entre outros. De forma unânime, nas entrevistas, a dificuldade financeira é um indicador de vulnerabilidade, com destaque para as dificuldades de inserção no mercado de trabalho e do acesso a benefícios, como o Bolsa Família, por parte de alguns usuários.

Revista RBBA $\mid$ Revista Binacional Brasil Argentina 
NA ASSISTÊNCIA SOCIAL DE NOVA FRIBURGO

Ao falarem sobre suas atribuições na Assistência Social, as profissionais afirmaram que faz parte da prática da psicóloga o fortalecimento de vínculos e ações preventivas através do acolhimento, encaminhamento, acompanhamento familiar, visitas domiciliares e trabalhos em grupo, tendo como objetivo principal retirar os usuários da situação de vulnerabilidade social. No entanto, quando solicitadas a descrever seu cotidiano nas instituições, as entrevistadas demonstraram exercer práticas diversas do que descreveram anteriormente como atribuições da psicóloga, tanto na proteção social básica quanto na especial. Algumas descreveram práticas voltadas predominantemente para o âmbito individual, identificando os trabalhos voltados para grupos como complementares, uma espécie de extensão do trabalho individual. Quando discutida a possibilidade de intervenção da Psicologia no âmbito comunitário, notamos que o maior potencial da prática psicológica, segundo elas, estaria nas intervenções voltadas para o âmbito individual, que por sua vez geraria efeitos no âmbito coletivo. Na análise do material, percebemos a primazia do indivíduo nas relações sociais, de modo que prevalece uma Psicologia voltada para o sujeito-indivíduo, apartado e em detrimento de suas relações constituintes.

Entrevistadora: Você entende que a Psicologia pode atuar no âmbito coletivo e comunitário?

Entrevistada: Espero que sim [risos].

Entrevistadora: E qual seria o papel ou contribuição da Psicologia nesse sentido?

Entrevistada: Eu entendo que o psicólogo tem um olhar para o indivíduo... que os outros profissionais não tem até pela formação, é um olhar por natureza que acolhe uma demanda e tenta compreender aquilo para além do ambiente, embora o ambiente contribua, ele tem um olhar para como esse indivíduo está nesse ambiente e por que dessa forma, e isso é de suma importância, porque se você só mexe naquela pessoa como se fosse coisa material, não terá muito resultado.

Embora as profissionais reconheçam suas atribuições enquanto psicólogas no âmbito da assistência social, não conseguem colocá-las em prática, pois o trabalho no contexto das políticas públicas, onde não cabem práticas individualizantes e psicologizantes, confronta-se com uma identidade profissional aparentemente hegemônica, gerando tensionamentos. $\mathrm{O}$ trecho de outra entrevista, a seguir, é um exemplo desse embate de representações da identidade profissional.

Entrevistada: Na Assistência Social, o psicólogo... ele meio que se mistura com a profissão de assistente social... Aqui a gente não desenvolve o pleno, a

Revista RBBA $\mid$ Revista Binacional Brasil Argentina 
função do [ênfase] psicólogo... a gente acaba tendo que fazer outras funções que não nos é ensinado muitas das vezes na faculdade. Aqui, por exemplo, eu posso fazer um atendimento específico e não um tratamento, tá? Eu recebo a pessoa, identifico a necessidade dela, vejo se é pertinente encaminhá-la para um tratamento psicológico e aí eu vou indicar outras instituições. Muitas das vezes, eu encaminho para a própria Estácio, lá para o SPA [Serviço de Psicologia Aplicada].

Entrevistadora: E quais dessas atividades que você falou que são da sua profissão, que você acha que se misturam com a da assistente social?

Entrevistada: Por exemplo, chega uma pessoa aqui com uma demanda, ela está enferma, não pode trabalhar, não tem condições de trabalhar e precisa dar entrada num benefício assistencial oferecido pelo governo. Então, teoricamente é cargo do assistente social fazer isso, só que eu, enquanto técnica, também posso fazer... não é específico, né... então eu acabo fazendo esse papel. (...) Então, pois é... pra mim enquanto psicóloga seria muito bom se eu pudesse fazer... sabe, assim... aquele atendimento individual, esquematizado, sabe? Assim, sistemático, ali, semanal... até poder chegar a dar alta pra esse paciente. Isso seria ótimo, porque muitas das vezes a gente encaminha e o paciente não tem como ir. Às vezes ele não tem condição financeira. Mesmo a gente encaminhando para o SPA na Estácio, onde é totalmente gratuito, ele não tem condições de arcar com o transporte pra chegar até lá.

Nessa entrevista, assim como nas demais, são notáveis os tensionamentos na identidade profissional hegemônica, a saber, aquela centrada no indivíduo e em práticas clínicoindividuais. Tais tensionamentos se destacam no âmbito da política pública, justamente onde se exige da profissional uma atuação não individualizante e psicologizante, integrada a equipes de trabalho multiprofissional e que incorpore como objeto de investigação os fenômenos sociais que parecem pouco relevantes à Psicologia tradicional (FREITAS, 2015). Este achado coaduna com a pesquisa realizada por Cordeiro e Curado (2017) com profissionais de Psicologia inseridas na Assistência Social, na qual concluem que haveria uma crise na identidade profissional, decorrente da falta de referenciais e que resultaria em uma prática que reproduz modelos clínicos, tornando evidentes as divergências entre o que é proposto pelas políticas sociais e o que é ensinado nas graduações de Psicologia.

Cabe ressaltar que, em nossa crítica a respeito da clínica que busca se fazer presente na práxis psicológica na assistência social, não pretendemos contestar as potencialidades da mesma, mas apontar para a necessidade de repensar uma clínica que se sustenta nos moldes de uma Psicologia tradicional. Apoiamo-nos em Andrade e Romagnoli (2010), que versam sobre a questão da psicologização dos problemas sociais, que reforça a dicotomia indivíduo $\mathrm{x}$ sociedade e nos leva à necessidade de questionar a apropriação de saberes e práticas culpabilizadoras. A clínica é social e deve ser ampliada, uma clínica "que se faz e refaz em 
NA ASSISTÊNCIA SOCIAL DE NOVA FRIBURGO

vários territórios" (ANDRADE; ROMAGNOLI, 2010, p. 611), construída com base na diversidade de profissionais, espaços e locais de trabalho, promovendo encontros singulares.

Ainda sobre a constatação de modelos clínico-individuais orientando a práxis psicológica na assistência social, cabe frisar que identificamos algumas exceções, como a da profissional que discorre sobre a atividade de busca ativa, que consistia em saídas pelo território para a construção de vínculos e identificação de demandas, desenvolvendo desse modo uma prática voltada para o âmbito comunitário e contextualizada com a realidade da comunidade. A atividade citada pela psicóloga vai de encontro com a discussão de Kasprovicz e Lima (2018), quando abordam o conceito de território como uma das diretrizes que devem orientar a atuação da Psicologia no SUAS. O trabalho no território é de suma importância para melhor compreensão sobre a população atendida e a constante reorientação das intervenções psicológicas. Estas, no entanto, podem transformar e emancipar ou reproduzir uma lógica normalizadora, o que exige contínua atenção e problematização das práticas.

Entrevistada: Quando a gente vai fazer alguma atividade fora, no território, ela é construída normalmente em cima de uma necessidade, daquele grupo, daquele território. Por exemplo (...), tem uma área aqui que tem um número grande de crianças que foram abusadas sexualmente (...). A gente tá fazendo contato com essas famílias, quer dizer, o objetivo é que a gente possa montar uma ação lá nessa área pra gente começar a discutir isso.

De todo modo, em nossa pesquisa, notamos que permanece nos discursos das profissionais uma cisão entre os atendimentos direcionados para psicólogas e para assistentes sociais, conforme também constatado na pesquisa de Andrade e Romagnoli (2010), realizada em um CRAS. Segundo as autoras, no campo investigado, a Psicologia é caracterizada como um "saber da psique", associada a questões de saúde e doenças mentais, enquanto a Assistência Social é caracterizada como uma "área social", voltada para dificuldades socioeconômicas (Ibid., p. 610). Desse modo, a Psicologia é compreendida dentro de um espaço fechado, entendimento que não se enquadra plenamente nas ações e intervenções empreendidas pelas políticas de Assistência Social. Corroborando com tal constatação, algumas profissionais entrevistadas afirmaram se sentir perdidas e confusas quanto à delimitação da prática psicológica em relação à da assistente social. Nesse desencontro identitário, são elencados o "olhar" e a "escuta" como especificidades do saber da psicóloga. Diversas entrevistas apresentaram tais especificidades, como as duas seguintes. 
Entrevistada: Hoje em dia, eu vejo que as pessoas que entram na Assistência Social e são psicólogos ficam meio perdidos. Até hoje eu fico meio perdida na minha função aqui, e isso é comum, vejo como comum porque a função do psicólogo meio que se confunde com a função do assistente social, porque a nossa prática é a mesma, o que nos diferencia mesmo é o nosso olhar, a nossa escuta, então aqui eu faço atendimento, o mesmo que uma assistente social pode fazer.

Entrevistada: Eu participo desse trabalho desde que eu entrei no serviço público. E até hoje [risos] eu estou nessa construção do papel do psicólogo na Assistência e é muito complicado. É muito complicado... Claro [ênfase] que tem especificidades no atendimento, em algumas situações... Agora, eu acho que fundamentalmente é o olhar que complementa. A diferença estará no olhar. Aqui, a gente trabalha [com] psicólogo e assistente social; então, eu tenho um olhar que é específico da minha formação e ela [assistente social] tem um olhar que é específico da formação dela. Na atuação concreta [ênfase], muitas vezes essas coisas se misturam, entendeu?

O "olhar" e a "escuta", termos que parecem diferenciar a profissional de Psicologia da profissional de Serviço Social, embora pouco especificados pelas entrevistadas, são objeto de análise de Sanches e Silva (2019). Em suas considerações sobre a terminologia "escuta qualificada", e tendo como panorama a atuação da Psicologia no SUAS, os autores argumentam que, num cenário neoliberal, corre-se "o risco das ações e instrumentais da política (como a própria escuta) serem tomados como meios de captura da subjetividade em prol de um modelo de sujeito e sociedade que coloca em marcha e naturaliza uma visão estigmatizante, discriminatória e que reitera as desigualdades social" (SANCHES; SILVA, 2019, p. 619). Nesse sentido, o uso indiscriminado e pouco refletido de termos como "escuta" pode dissimular propósitos estritamente diagnósticos, reforçando cenários de controle e ajustamento sociais.

No decorrer da análise das entrevistas, o tensionamento - e eventualmente também a fluidez - das representações da identidade profissional parece decorrente, ainda que em parte, do desencontro entre a formação em Psicologia - voltada hegemonicamente para o âmbito individual, fundamentada em referenciais clínico-individuais - e o que é esperado em uma política socioassistencial. De maneira semelhante, em sua pesquisa, Cordeiro e Curado (2017) constataram que uma das críticas mais recorrentes no discurso dos profissionais foi a questão de a formação desconsiderar a prática psicológica inserida no campo das políticas sociais.

Em nossa pesquisa, algumas profissionais relataram que, quando adentraram as políticas públicas, especialmente a socioassistencial, perceberam-se num aparente vazio de referências teórico-metodológicas para fundamentar sua prática, resultando em dificuldades em atender demandas de caráter coletivo e de intervir em contextos comunitários. Seguem dois exemplos.

Revista RBBA Revista Binacional Brasil Argentina 
Entrevistada: A minha formação foi estritamente clínica eu tive uma experiência somente em Psicologia escolar... mas basicamente [ênfase] a minha formação foi em clínica e aí quando eu comecei a atuar, atuei em Posto de Saúde, no Ambulatório... atendimento clínico, e em seguida eu vim para a área de Assistência [Social], que eu me senti um peixe fora d'água, por conta da nossa experiência profissional. Mas a gente acaba estudando, se aperfeiçoando e se adequando.

Entrevistada: Eu sou psicóloga do CRAS e aqui a gente faz atendimento social. Normalmente o psicólogo que entra na Assistência Social tem uma certa dificuldade, porque a formação nos direciona muito para a Psicologia clínica. Quando eu entrei aqui, eu não sabia nada, tive que aprender tudo na prática mesmo.

Quando questionadas se a Psicologia pode ou deve atuar, por exemplo, no âmbito comunitário, todas as profissionais responderam positivamente. No entanto, ao serem perguntadas como isso poderia ser feito e qual seria a contribuição da Psicologia, houve considerável dificuldade em responder. Algumas relataram que a contribuição da Psicologia é oferecer a escuta, de modo a motivar a pessoa a sair da realidade na qual ela se encontra. Outras relataram que a contribuição se dá através da conscientização e construção de estratégias para a saída da condição de vulnerabilidade. Outras especificaram que a contribuição consiste em esclarecimento, informação e rodas de conversa com o objetivo de promover conscientização e empoderamento.

É possível notar em alguns desses discursos uma relativa individualização de questões sociais, quando as profissionais afirmam que para sair da condição de vulnerabilidade social basta que estes sujeitos sejam motivados e superem, por si sós, as condições nas quais se encontram. Desse modo, parecem ignorar ou desconhecer os fatores sociais que atravessam os sujeitos e a realidade na qual estão inseridos. Também é possível perceber que prevalece a visão de uma Psicologia salvacionista, especialmente quando afirmam que sua contribuição profissional é conscientizar e levar conhecimento e esclarecimento para a comunidade, expressando uma prática baseada em uma hierarquia entre o saber psi especializado e os saberes locais.

A precarização institucional e o sucateamento das políticas públicas também atravessam a prática psicológica na assistência social (DETTMANN; ARAGÃO; MARGOTTO, 2016). Não obstante, a análise temática e a análise categorial permitiram identificar que o discurso da precarização colocou na penumbra a dificuldade das profissionais de Psicologia em atender demandas de caráter coletivo, como intervenções em contextos comunitários, tendo em vista Revista RBBA Revista Binacional Brasil Argentina 
NA ASSISTÊNCIA SOCIAL DE NOVA FRIBURGO

que a formação, conforme tratado ao longo do texto, parece ainda fortemente voltada para o âmbito individual. Nesse sentido, duas formas de precariedade - a institucional e a formativa pareciam se relacionar. De um lado, a atuação profissional limitada a intervenções pontuais e de cunho individualista parece reforçada por uma conjuntura de precarizações dos serviços como precariedade da infraestrutura e dos contratos de trabalho, assim como a escassez de recursos materiais e humanos. De outro, tal atuação também parece remeter a precarizações ou limitações na própria formação profissional. Nas respostas voltadas para o delineamento da formação e da prática profissionais, constatam-se limitações na compreensão de princípios fundantes da vida societal, assim como a contribuição desses princípios na construção dos processos psicossociais, nos planos micro e macrossocial, embasamento teórico determinante para a constituição dos aportes necessários à atuação da Psicologia nas políticas sociais. Tal precarização na formação parece explicar em parte a dificuldade das profissionais em apreender ou vislumbrar uma Psicologia para além do indivíduo e dos espaços institucionais.

Nesse sentido, os embates em torno da identidade profissional sugerem que as profissionais estejam às voltas com o lugar que ocupam na assistência social. Em outros termos, esse lugar tensiona a práxis psicológica na assistência social, aparentemente repercutindo e gerando indagações na construção identitária da profissão. Em consonância com a discussão de Luz (2018), parece-nos que o maior desafio da Psicologia na política de assistência social é reconhecer a amplitude de seu lugar no SUAS, o que implica necessariamente em reflexões sobre o fazer.

\section{Considerações finais}

Diante do exposto, compreendemos que a atuação da Psicologia nas políticas públicas de assistência social de Nova Friburgo se encontra em delicada construção. A partir da análise realizada, foi possível constatar que a formação na área parece ainda não oferecer aportes teórico-metodológicos para a atuação das profissionais no âmbito das políticas públicas, em especial nas de assistência social. Apontamos que tal deficiência na formação se reflete nas dificuldades do trabalho dessas profissionais. Tais dificuldades se expressam na forma de tensionamentos da identidade profissional, que por sua vez parecem se relacionar a práticas descontextualizadas e individualizantes. 

NA ASSISTÊNCIA SOCIAL DE NOVA FRIBURGO

A categoria identidade profissional, apresentada e discutida no presente recorte, delineou o perfil das profissionais entrevistadas, perfil que é ativamente construído por elas, enquanto as subcategorias formação e prática remeteram a diferentes aspectos que integram e fundamentam essa identidade. Como vimos, essas categorias formam uma práxis da Psicologia no contexto da assistência social, e suas relações expressam tensionamentos que muito falam dos desencontros de certa Psicologia, leia-se hegemônica, nas políticas públicas de assistência social. Em alguns desses casos, vimos que a profissional pode "estudar, se aperfeiçoar e se adequar", conforme dito por uma entrevistada, o que parece remeter a uma precarização da formação. No entanto, ela também pode adequar a realidade à sua identidade, ao seu modo de fazer, conforme argumentado por outra entrevistada, que faz referência ao trabalho sob uma perspectiva clínico-individual.

A análise das entrevistas realizadas também possibilitou um diagnóstico das práticas psicológicas no contexto da assistência social e apontou que as profissionais, em sua maioria, não atuam de acordo com as diretrizes básicas dos equipamentos e serviços. Notou-se, por exemplo, uma dificuldade no estabelecimento de vínculos e parcerias com a comunidade local, de modo que os equipamentos socioassistenciais, que deveriam atuar como unidades de referência no território, atuam de modo isolado, aparentemente à deriva nas comunidades. Desse modo, faz-se necessário o estabelecimento de estratégias de vinculação, como criação de encontros com membros e representantes da comunidade, de oficinas e atividades externas, promovendo uma readequação das ações e serviços de acordo com as realidades locais.

Os achados desta pesquisa encontram eco na bibliografia especializada, onde permanecem considerações a respeito do desafio em repensar saberes e práticas psicológicas no âmbito das políticas socioassistenciais, assim como a necessidade de ampliar a temática na formação (MOTTA; SCARPARO, 2013; CORDEIRO; CURADO, 2017; CORDEIRO; SATO, 2017; CORDEIRO, 2016; FLORENTINO; MELO, 2017; MACÊDO et al., 2015). A constatação de algumas profissionais entrevistadas quanto ao desconhecimento do campo antes da entrada nos equipamentos e serviços indica a importância da inclusão das políticas públicas socioassistenciais nos currículos. Pontuamos, portanto, que a produção de conhecimento dentro da Psicologia deve permanecer abrangendo as problemáticas levantadas, a fim de reconsiderar os modelos teórico-metodológicos vigentes, permitindo a construção de novos caminhos. 
NA ASSISTÊNCIA SOCIAL DE NOVA FRIBURGO

\section{REFERÊNCIAS}

ANDRADE, L. F.; ROMAGNOLI, R. C. O psicólogo no CRAS: uma cartografia dos territórios subjetivos. Psicologia: Ciência e Profissão, v. 30, n. 3, p. 604-619, 2010. Doi: https://doi.org/10.1590/S1414-98932010000300012. Acesso em: 6 nov. 2020.

BARDIN, L. Análise de conteúdo. Lisboa: Edições 70, 2016.

BRASIL. Equipes de Referências no Âmbito do Sistema Único de Assistência Social. Brasília: Ministério do Desenvolvimento Social e Combate à Fome, Secretaria Nacional de Assistência Social, 2010.

BRASIL. Norma Operacional Básica de Recursos Humanos NOB-RH-SUAS. Brasília: Ministério do Desenvolvimento Social e Combate à Fome, 2006.

BRASIL. Norma Operacional Básica NOB-SUAS. Brasília: Ministério do Desenvolvimento Social e Combate à Fome, 2005.

BRASIL. Política Nacional de Assistência Social - PNAS. Brasília: Ministério do Desenvolvimento Social e Combate à Fome, 2004.

CONSELHO FEDERAL DE PSICOLOGIA. Nota técnica com parâmetros para atuação das (os) profissionais de psicologia no âmbito do Sistema Único de Assistência Social (SUAS). Brasília: CFP, 2016.

CONSELHO FEDERAL DE PSICOLOGIA. Psicologia: uma profissão de muitas e diferentes mulheres. Brasília: CFP, 2013.

CORDEIRO, M. P. A psicologia no SUAS: uma revisão de literatura. Arquivos Brasileiros de Psicologia, v. 70, n. 3, p. 166-183, 2018. Disponível em: http://pepsic.bvsalud.org/pdf/arbp/v70n3/12.pdf. Acesso em: 6 nov. 2020.

CORDEIRO, M. P.; CURADO, J. C. Psicologia na assistência social: um campo em formação. Psicologia \& Sociedade, v. 29, p. 1-11, 2017. Doi: https://doi.org/10.1590/18070310/2017v29169210. Acesso em: 6 nov. 2020.

CORDEIRO, M. P.; SATO, L. Psicologia na política de assistência social: trabalho em um "setor terceirizado". Estudos de Psicologia, v. 34, n. 1, p. 41-52, 2017. Doi: https://doi.org/10.1590/1982-02752017000100005. Acesso em: 6 nov. 2020.

DETTMANN, A. P. S.; ARAGÃO, E. M. A.; MARGOTTO, L. R. Uma perspectiva da clínica ampliada: as práticas da Psicologia na assistência social. Fractal: Revista de Psicologia, v. 28, n. 3, p. 362-369, 2016. Doi: https://doi.org/10.1590/1984-0292/1232. Acesso em: 6 nov. 2020.

FLORENTINO, B. R. B.; MELO, W. A inserção da Psicologia no sistema único de assistência social: notas introdutórias. Revista Interinstitucional de Psicologia, v. 10, n. 1, p. 3-12, 2017. Disponível em: http://pepsic.bvsalud.org/pdf/gerais/v10n1/02.pdf. Acesso em: 6 nov. 2020. 
FREITAS, M. F. Q. Práxis e formação em Psicologia Social Comunitária: exigências e desafios ético-políticos. Estudos de Psicologia, v. 32, n. 3, p. 521-532, 2015. Doi: https://doi.org/10.1590/0103-166X201500300017. Acesso em: 6 nov. 2020.

FREITAS, M. F. Q. Psicologia na comunidade, psicologia da comunidade e psicologia (social) comunitária: Práticas da Psicologia em comunidade nas décadas de 1960 a 1990, no Brasil. In: CAMPOS, R. H. F. (org.). Psicologia social comunitária: da solidariedade à autonomia. 19. ed. Petrópolis, RJ: Vozes, 2007. p. 44-65.

KASPROVICZ, M.; LIMA, A. B. Psicologia, territorialização e Assistência Social. Anais do I Congresso do Programa de Pós-Graduação em Psicologia da UEL. Londrina: UEL, 2018. p. $97-101$.

LUZ, R. R. A construção de saberes e práticas em psicologia no Centro de Referência Especializado de Assistência Social (CREAS) de Guapimirim. Psicologia Revista, v. 27, n. 2, p. 337-355, 2018. Doi: http://dx.doi.org/10.23925/2594-3871.2018v27i2p337-355. Acesso em: 6 nov. 2020.

MACÊDO, O. J. V.; ALBERTO, M. F. P.; SANTOS, D. P.; SOUZA, G. P; OLIVEIRA, V. S. Ações do profissional de Psicologia no Centro de Referência da Assistência Social. Psicologia: Ciência e Profissão, v. 35, n. 3, p. 809-823, 2015. Doi: https://doi.org/10.1590/19823703001632013. Acesso em: 6 nov. 2020.

MENZ, D. M.; CAMARGO, D. Psicólogos nas políticas públicas de assistência social: atuação em CRAS e interface com a formação acadêmica. Psicologia Argumento, v. 38, n. 101, p. 431449, 2020. Doi: http://dx.doi.org/10.7213/psicolargum.38.101.AO02. Acesso em: 6 nov. 2020.

MOTTA, R. F.; SCARPARO, H. B. K. A psicologia na assistência social: transitar, travessia. Psicologia \& Sociedade, v. 25, n. 1, p. 230-239, 2013. Doi: http://dx.doi.org/10.1590/S010271822013000100025. Acesso em: 6 nov. 2020.

PEREIRA, D. Z.; ROCHA, S. F. M.; CHAVES, P. M. O conceito de práxis e a formação docente como ciência da educação. Revista de Ciências Humanas - Educação, v. 17, n. 29, p. 2016. 31-45, Disponível em: http://revistas.fw.uri.br/index.php/revistadech/article/view/2307. Acesso em: 6 nov. 2020.

ROMAGNOLI, R. C. Algumas reflexões acerca da clínica social. Revista do Departamento de Psicologia da UFF, v. 18, n. 2, p. 47-56, 2006. Doi: https://doi.org/10.1590/S010480232006000200004. Acesso em: 6 nov. 2020.

SANCHES, N.; SILVA, R. B. A escuta qualificada na assistência social: da postura diagnóstica às formas (po)éticas de escutar. Estudos e Pesquisas em Psicologia, v. 19, n. 3, p. 604-622, $2019 . \quad$ Disponível em: https://www.epublicacoes.uerj.br/index.php/revispsi/article/view/46905. Acesso em: 6 nov. 2020.

SCOTT, J. B.; MARION, J.; FREITAS, A. P. M.; FERREIRA, M.; PEREIRA, C. R. R.; SIQUEIRA, A. C. Desafios da atuação do psicólogo em centros de referência da assistência 
social (Cras). Gerais: Revista Interinstitucional de Psicologia, v. 12, n. 1, p. 125-141, 2019. Doi: https://dx.doi.org/10.36298/gerais2019120110. Acesso em: 6 nov. 2020.

YAMAMOTO, O. H.; OLIVEIRA, I. F. Política social e Psicologia: uma trajetória de 25 anos. Psicologia: Teoria e Pesquisa, v. 26, número especial, p. 9-24, 2010. Doi: https://doi.org/10.1590/S0102-37722010000500002. Acesso em: 6 nov. 2020.

\section{Notas}

\footnotetext{
${ }^{i}$ Agência financiadora: Programa Pesquisa Produtividade da Universidade Estácio de Sá.

ii No presente texto, o uso do termo no gênero feminino se refere ora às entrevistadas do recorte analisado, todas mulheres, ora à categoria profissional, que inclui homens e mulheres. Seu uso também se justifica pelo posicionamento político de explicitar a categoria como majoritariamente feminina, conforme atestado em pesquisa do Conselho Federal de Psicologia (CFP, 2013).

${ }^{i i i}$ A informação está disponível na página www.cidades.ibge.gov.br.
} 